\title{
The latest mathematical and empirical models to calculate the thermal conductivity of the soils
}

\author{
Agnieszka Drzyzga ${ }^{*}$ \\ ${ }^{1}$ Faculty of Environmental and Power Engineering, Cracow University of Technology, al. Jana Pawła II 37, 31-864 Kraków, Poland
}

\begin{abstract}
The paper presents the latest models for calculating the thermal conductivity of soil. Precise determination of this parameter is necessary for the correct and safe location of geoengineering objects, underground infrastructure such as cables or ground heat exchangers. A universal model that is easy to apply and gives the most accurate results has not yet been developed. New models are constantly being developed. The aim of this work is to present the latest models for calculating thermal conductivity, so that knowing the properties of the soil, it is possible to select an appropriate model to calculate its conductivity.
\end{abstract}

\section{Introduction}

Correct determination of the thermal parameters of the ground is of great importance for the safe and ergonomic location of the geoconstruction, underground infrastructure such as cables, pipelines, ground heat exchangers. The basic thermal properties of soil are thermal conductivity, thermal diffusivity and heat capacity [1]. The main mechanism by which heat flows through the ground is conduction. Convection plays a significant role only in very well-drained soils, such as gravel [2]. Radiation is relevant only for surface soils. The basic parameter describing the heat transfer in the soil is the thermal conductivity of the soil. It is a measure of a soil's ability to transfer heat due to a temperature difference and depends on many factors such as humidity, dry density, mineralogy, particle size distribution, time and temperature [1]. Despite the fact that there are many methods of measuring the thermal conductivity of the soil (e.g. the heat plate method, the thermal pulse method, the linear source method), the direct measurement of the thermal conductivity of the soil may turn out to be impractical in large-scale studies due to the time-consuming, labor-intensive and relatively high costs. During the last few decades, many models for calculating the thermal conductivity of the soil have been developed [3]. These models are empirical or theoretical/mathematical, with most theoretical models having been empirically modified, resulting in semi-empirical models [4]. Empirical models (e.g., de Vries (1963); Gemant (1952); Johansen (1975); Kersten (1949); Kunii and Smith (1960); McGaw (1969); Mickley (1951); Smith (1942); Van Rooyen and Winterkorn (1959); Woodside and Messmer (1961)) are based on the analysis of the measured thermal conductivity of the soil as a function of easily measurable soil parameters such as soil water saturation and density [3]. Theoretical/ mathematical models treat the soil as a three-phase system consisting of air, water and a mineral part [5]. These models are based on other physical models designed to describe other soil properties and have a complex computational process [1]. The aim of this article is to review the latest mathematical and empirical models for calculating the thermal conductivity of the soil.

\section{Models of thermal conductivity of soil}

There are many models available in the literature for calculating the thermal conductivity of the soil. Comparisons of the available methods of determining the thermal conductivity of soils were undertaken, among others, by Farouki [6], He et al. [7], Rerak [8], Zhang [9], Różański [10]. Farouki [6] compiled and compared 11 methods for determining the thermal conductivity of soil, incl. Kersten [11], de Vries and Afgan [12, 13] and Johansen [14]. He took into account soils of various grain size (fine-grained and coarsegrained) and water content in the soil. According to Farouki [6], the Johansen method [14] works best for fine-grained, unfrozen soils, while with a saturation below $20 \%$, the original Johansen method lowers the thermal conductivity by about $5-15 \%$ [15]. In such a case, better results are obtained by applying the modified Johansen method described by Peters-Lidard et al. [16]. Zhang [9] analyzed 13 predictive models and assessed their performance for sands under varying humidity conditions. The best results were obtained when the Zhang et al. [17] model were used, Chen [18], and Haigh [19]. Różański [10] compiled 15 models, as well as different approaches used for the Kersten number and the conductivity of dry and saturated soil presented by Cote and Konrad [20,21], Lu et al. [22], He

*Corresponding author: agnieszka.drzyzga@doktorant.pk.edu.pl 
et al. [23]. Despite the fact that there are many models for calculating the thermal conductivity of the soil, more are still being developed in order to create a model that is universal, easy to apply and gives the most accurate forecasts.

\section{Review of the latest models of soil thermal conductivity}

The latest calculation models for the thermal conductivity of soils are presented below. This compilation includes mathematical and empirical models. Numerical models are also included.

\subsection{Empirical models}

Empirical models are created based on the numerical or analytical analysis of experimental data between the effective thermal conductivity and easily measurable soil properties such as moisture, bulk density or degree of saturation. Their credibility largely depends on the accuracy of the experimental data. However, the application of empirical models should be narrowed down to the soil types or geomorphological regions on which they were developed, as they are difficult to apply to soils outside the studied range of saturation levels, bulk density or textures [23].

\subsubsection{The model of Lu and Dong [24]}

Lu and Dong [24] proposed an innovative closed equation for thermal conductivity as a function of water content. They investigated the influence of all types of soil and humidity on thermal conductivity when the ambient temperature is within $20-25 \mathrm{oC}$. In the proposed equation, Lu and Dong [24] took into account soil-water retention regimes. The equation was verified on the basis of 27 different types of soil presented from literature and research. It has the form:

$$
\frac{k-k_{d r y}}{k_{s a t}-k_{d r y}}=1-\left[1+\left(\frac{s_{r}}{s_{f}}\right)^{m}\right]^{1 / m-1}
$$

where $\mathrm{k}$ is the thermal conductivity of the soil [W/mK], $\mathrm{k}_{\mathrm{dry}}, \mathrm{k}_{\mathrm{sat}}$ are the dry and saturated thermal conductivity, respectively $[\mathrm{W} / \mathrm{mK}], \mathrm{S}_{\mathrm{r}}$ is the degree of saturation, $\mathrm{S}_{\mathrm{f}}$ is the degree of saturation at which the cableway regime begins (mainly water desaturation occurs ) and $\mathrm{m}$ determines the connectivity of the fluid network and represents the rate of change of thermal conductivity with a water content. $\mathrm{S}_{\mathrm{f}}$ and $\mathrm{m}$ are fit parameters that can be related to the behavior of water in the soil.

\subsubsection{The model of Zhang et al. [25]}

Based on the concept of normalized $\mathrm{K}_{\mathrm{e}}$ thermal conductivity presented by Johansen [14], as well as the $\mathrm{Ke}-\mathrm{Sr}$ relation taking into account the influence of the soil type proposed by Cote and Konrad [20,21], Zhang et al. [25] proposed a model of thermal conductivity for quartz sands:

$$
k=\left(k_{w}^{n} k_{s}^{1-n}-\chi 10^{-\eta n}\right)\left[\frac{\kappa S_{r}}{1+(\kappa-1) S_{r}}\right]+\chi 10^{-\eta n}
$$

where $\mathrm{k}_{\mathrm{s}}$ is the thermal conductivity of the solid particles $[\mathrm{W} / \mathrm{mK}], \mathrm{n}$ is the porosity, $\kappa$ is the parameter depending on the soil texture, $\eta$ and $\chi$ are the shape dependent coefficients.

\subsubsection{The model of Zhang et al. [26]}

Zhang et al. [26] proposed a generalized model of soil thermal conductivity based on laboratory tests. They considered pure sands with a quartz content of $99 \%$, kaolin clays and mixtures of sand and kaolin clay in various proportions, with different porosity and degrees of saturation. Zhang et al. [26] presented a new relationship between $\mathrm{k}_{\mathrm{r}}-\mathrm{S}_{\mathrm{r}}$ as follows:

$$
k_{r}=\frac{\left(2.168 \cdot 10^{-5} \cdot \exp \left({ }^{q} / 7.903\right)+1.252\right) S_{r}}{1+\left(2.168 \cdot 10^{-5} \cdot \exp \left({ }^{q} / 7.903\right)+0.252\right) S_{r}},
$$

where, $\mathrm{q}$ is the quartz (sand) content [\%]. For $\mathrm{k}_{\mathrm{dry}}$ and $\mathrm{k}_{\mathrm{sat}}$ the following equations were proposed:

$$
\begin{gathered}
k_{\text {dry }}=\left(1.216 \cdot 10^{-6} \cdot \exp (q / 6.599)+3.034\right) \\
10^{(-0.003 \cdot \exp (q / 1.452)-1.840) \cdot n} \\
k_{\text {sat }}=k_{w}^{n}\left(k_{q}^{q / 100} k_{\text {kaolin }}^{1-q / 100}\right)^{1-n}
\end{gathered}
$$

where $\mathrm{k}_{\mathrm{q}}$ is the thermal conductivity of quartz and $\mathrm{k}_{\mathrm{kaolin}}$ is the thermal conductivity of kaolin clays and their values are 7,5 $[\mathrm{W} / \mathrm{mK}]$ and $2,9[\mathrm{~W} / \mathrm{mK}]$, respectively. Proposed by Zhang et al. [26] the new generalized model of thermal conductivity is as follows:

$$
\begin{gathered}
k=\frac{\left(2.168 \cdot 10^{-5} \cdot \exp (q / 7.903)+1.252\right) s_{r}}{1+\left(2.168 \cdot 10^{-5} \cdot \exp (q / 7.903)+0.252\right) S_{r}} . \\
{\left[k_{w}^{n}\left(k_{q}^{q / 10} k_{k a o l i n}^{1-q / 100}\right)^{1-n}-\left(1.216 \cdot 10^{-6}\right.\right.} \\
\exp (q / 6.599)++3.034) \cdot \\
10^{(-0.003 \cdot \exp (q / 16.452)-1.840) \cdot n]+\left(1.216 \cdot 10^{-6} .\right.} \\
\exp (q / 6.599)+3.034) \cdot \\
10^{(-0.003 \cdot \exp (q / 16.452)-1.840) \cdot n} .
\end{gathered}
$$

This model takes into account the influence of factors such as porosity and degree of saturation, as well as quartz content and soil type, on the thermal conductivity of soils.

\subsubsection{The model of Tarnawski and Leong [27]}

Tarnawski and Leong [27] developed an advanced geometric mean model (A-GMM) to calculate the effective thermal conductivity $k_{\text {eff }}$ of unsaturated soils based on the thermal resistance coefficient of intermolecular contact, the degree of saturation of a small pore space and the thermal conductivity of the soil skeleton:

$$
k_{e f f}=\left[\alpha k_{s}\right]^{1-n}\left[k_{w}\right]^{n S_{r}}\left[k_{a}\right]^{n\left(1-S_{r}\right)},
$$

where $\alpha$ is the coefficient of intermolecular contact resistance, $\mathrm{k}_{\mathrm{s}}$ is the thermal conductivity of the soil 
skeleton $[\mathrm{W} / \mathrm{mK}], \mathrm{k}_{\mathrm{a}}$ is the thermal conductivity of the air $[\mathrm{W} / \mathrm{mK}]$.

\subsubsection{The Model of Tong et al. [28]}

Tong et al. [28] proposed a simple model for estimating the thermal conductivity of the soil, which requires only two input parameters such as porosity and water volume content:

$$
k(\theta)=a-b \exp (-c \theta)
$$

where $\theta$ is the volumetric humidity, $a$ and $b$ are empirical parameters, and the parameter $\mathrm{c}$ is 3.90 . The application of the model is limited only to soils with porosity in the range of 0.40 to 0.55 .

\subsubsection{The model of He et al. [23]}

He et al. [23] based on the models of van Genuchten (van Genuchten, 1980) and Lu et al. [22,24] proposed a new standardized model for estimating the thermal conductivity of soil. They proposed a linear function to calculate the thermal conductivity of dry soil on the basis of porosity. The Kersten number $\mathrm{K}_{\mathrm{e}}$ is expressed as:

$$
\begin{gathered}
K_{e}=0, \theta=0 \\
K_{e}=\left[A \cdot \exp \left(\theta^{-B}\right)\right]^{-1}, \theta>0
\end{gathered}
$$

where $\mathrm{A}$ and $\mathrm{B}$ are the fit parameters. The new model is as follows:

$$
\begin{gathered}
k_{e f f}=k_{d r y}, \quad \theta=0 \\
k_{e f f}=k_{d r y}+\left(k_{s a t}-k_{d r y}\right) /\left[A \cdot \exp \left(\theta^{-B}\right)\right], \theta>0 .
\end{gathered}
$$

The thermal conductivity of saturated and dry soils is calculated from the equations:

$$
k_{s a t}=k_{s}^{1-n} k_{w}^{n} \mathrm{i} k_{d r y}=-a n+b,
$$

where $a$ and $b$ are empirical parameters.

\subsubsection{The model of Zhao et al. [3]}

Zhao et al. [3] proposed a new, generalized model for studying the thermal conductivity of soil, which takes into account the influence of porosity, degree of saturation, organic matter content and soil texture on its thermal conductivity. The model is applicable to soils of various textures and all degrees of water saturation and takes the form of a logarithmic equation:

$$
k=A_{1}+B_{1} \ln \left(1+S_{r}\right)
$$

where $A_{1}$ and $B_{1}$ are parameters depending on the composition, structure and texture of the soil, $\ln$ is the natural logarithm function and $S_{r}$ is the degree of saturation which takes into account the effect of the soil bulk density. The $A_{1}$ parameter depends on the soil porosity and expresses the thermal conductivity of dry soil, while the $\mathrm{B}_{1}$ parameter depends on the texture and structure of the soil, as well as the difference between the dry and saturated thermal conductivity. The parameters $\mathrm{A}_{1}$ and $\mathrm{B}_{1}$ are derived directly from the lower and upper boundary conditions as follows:

lower boundary condition: $S_{r}=0=>k=k_{d r y}$ i $k=A_{l}=>$ $A_{l}=k_{d r y}$

upper boundary condition: $S_{r}=1=>k=k_{s a t}$ i $k=k_{d r y}+$ $B_{1} \times \ln (2) \Rightarrow B_{1}=\left(k_{s a t}-k_{d r y}\right) / \ln (2)$

thus the thermal conductivity equation is written as follows:

$$
k=k_{d r y}+\left(k_{s a t}-k_{d r y}\right) \log _{2}\left(1+S_{r}\right) .
$$

The two-phase model of the geometric mean by Cote and Konrad was used to estimate the $\mathrm{k}_{\text {dry }}$ and the $\mathrm{k}_{\text {sat }}$ $[20,21]$.

\subsubsection{The model of Wang et al. [29]}

With an increase in the amount of precipitated $\mathrm{CaCO} 3$, the dry density of the soil increases, as well as the thermal conductivity of the soil. In order to study the thermal conductivity of sands, Wang et al. [29] subjected them to a microbial calcite recovery (MICP) treatment. The thermal conductivity of both untreated and treated sands at various degrees of saturation in the drying process was measured. Since the $k$ of the MICPtreated sand is higher than that of the crude sand, the improvement in thermal conductivity of sand I was calculated from the equation:

$$
I=\frac{k_{\text {treated }}-k_{\text {untreated }}}{k_{\text {untreated }}} \times 100 \%,
$$

where $\mathrm{k}_{\text {treated }}$ is the thermal conductivity of the treated sand $[\mathrm{W} / \mathrm{mK}], \mathrm{k}_{\text {untreated }}$ is the thermal conductivity of the raw sand [W/mK]. Wang et al. [29] based on the Cote and Konrad equation $[20,21]$ they proposed a modified predictive model of thermal conductivity for sands treated with MICP:

$$
\begin{aligned}
& k_{\text {nowe }}=\left(k_{w}^{n} k_{s}^{1-n}-\chi 10^{-\eta n}\right)\left[\frac{\kappa S_{r}}{1+(\kappa-1) S_{r}}\right]+\chi 10^{-\eta}+ \\
& 0.165 N
\end{aligned}
$$

where $\mathrm{k}_{\mathrm{w}}=0.59[\mathrm{~W} / \mathrm{mK}] ; \mathrm{k}_{\mathrm{s}}=2.26[\mathrm{~W} / \mathrm{mK}]$ is calculated from the formula proposed by Johansen $\mathrm{k}_{\mathrm{s}}=2.0^{1-q} \cdot 7.7^{q}$, where $\mathrm{q}$ is the quartz content, $\mathrm{N}$ is the number of treatment cycles. This model is only applicable to sands with a similar mineral composition to the sands tested, the grains of which are similar in size, shape and gradation.

\subsubsection{The model of Li et al. [30]}

Li et al. [30] developed a model for calculating the thermal conductivity of soils in the permafrost region. The authors conducted research in the Tibetan Plateau with a local average altitude of over 5100 m n.p.m. above sea level. The following parameters were measured during the tests: soil heat flux $\mathrm{Q}_{\mathrm{s}}$, air temperature $T_{a}$, soil temperature $T_{s}$, water vapor pressure WVP and soil moisture $\mathrm{w}$. Based on in situ measurements 1309 samples Li et al. [30] developed a 
model to predict the thermal conductivity of soil based on the variability of $\mathrm{T}_{\mathrm{s}}$ and $\mathrm{w} / \mathrm{WVP}$. The function looks like this:

$$
\begin{gathered}
k=1.237+0.002 T_{0}-0.007 T_{a}+1.928 \mathrm{w}, \\
k=1.410+0.008 T_{0}-0.007 T_{a}+0.025 W V P,
\end{gathered}
$$

where $T_{0}$ is the surface temperature of the ground, $T_{a}$ is the air temperature, $w$ is soil moisture and WVP is the pressure of the water vapor surface. The second equation was found to be more convenient to use because the WVP measurement was more readily available.

\subsubsection{The model of Tian et al. [31]}

Tian et al. [31] presented the relationship between the thermal conductivity of partially frozen soils and the pores filled with air $n_{a}$. The proposed exponential relationship between $\mathrm{k}-\mathrm{n}_{\mathrm{a}}$ has the following form:

$$
k=3.14 e^{-4.92 n_{a}} .
$$

The model is easy to use, it ignores the influence of temperature on the thermal conductivity of frozen soil and works best for soils with a temperature not greater than $-4^{\circ} \mathrm{C}$.

\subsubsection{The model of Tian et al. [32]}

Tian et al. [32] presented the correlation between thermal conductivity and geophysical parameters such as wave velocity and wave density. Using exponential fit, they determined the relationship between thermal conductivity and wave velocity:

$$
k=1.2878 e^{0.0003 V_{s}},
$$

where $\mathrm{k}$ is the thermal conductivity $\left[\mathrm{W} / \mathrm{m}^{\circ} \mathrm{C}\right]$ and $\mathrm{V}_{\mathrm{s}}$ represents the wave velocity $[\mathrm{m} / \mathrm{s}]$. They also determined the relationship between thermal conductivity and density:

$$
k=0.1453 e^{1.2156 \rho},
$$

where $\rho$ is the density at the appropriate depth. These correlations make it possible to determine the thermal conductivity quickly, economically and non-invasively of any zone in which no tests have been performed.

\subsubsection{The model of Xiao et al. [33]}

Xiao et al. [33] proposed an empirical equation taking into account the general relationship between the porosity coefficient and the relative density by taking into account the influence of the shape of the particles:

$$
\begin{gathered}
k=k_{e 0}-\chi_{e}\left(e_{\max }^{0}+\chi_{\max }^{e} O_{R}\right)+\chi_{e} I_{D}\left(e_{\max }^{0}-\right. \\
\left.e_{\min }^{0}\right)+\chi_{e} I_{D} 0_{R}\left(\chi_{\max }^{e}-\chi_{\min }^{e}\right),
\end{gathered}
$$

where $\mathrm{I}_{\mathrm{D}}$ is the relative density, $\mathrm{k}_{\mathrm{e} 0}, \chi_{\text {max }}^{e}, \chi_{\text {min }}^{e}, e_{\text {max }}^{0}$, $e_{\min }^{0}$ are the fit parameters and $\mathrm{O}_{\mathrm{R}}$ is the particle shape parameter.

\subsubsection{The model of Song et al. [34]}

The model for determining the thermal conductivity of unsaturated clays presented by Song et al. [34] takes into account the shares of individual minerals in the soil as well as the content of water and air in the soil pores. The assumption of the model is an even distribution of solid particles water and air in the soil and the basic unit of soil is represented by spheres each of which consists of a solid, liquid and gas phase. The equation for calculating the thermal conductivity of unsaturated clay is as follows:

$$
k=(\sqrt[3]{1-n}+\sqrt[3]{n}) k_{s}^{1-n} k_{w}^{n S_{r}} k_{a}^{n\left(1-S_{r}\right)},
$$

where $\mathrm{k}_{\mathrm{s}}$ is the thermal conductivity of the solid phase and is $k_{s}=\prod_{j} k_{m_{j}}^{x_{j}}=3.669[\mathrm{w} / \mathrm{mK}], \quad$ thermal conductivity of liquid $\mathrm{k}_{\mathrm{w}}=0.599[\mathrm{~W} / \mathrm{mK}]$ and the thermal conductivity of air $\mathrm{k}_{\mathrm{a}}=0.024[\mathrm{~W} / \mathrm{mK}]$. The model has not been verified for frozen soils and for high temperature underground soils.

\subsubsection{The model of Sun et al. [35]}

Sun et al. [35] developed a model of thermal conductivity and electrical resistance for silty clays in the temperature range $-20^{\circ} \mathrm{C}$ to $10^{\circ} \mathrm{C}$. For frozen soil, the equation of thermal conductivity is as follows:

$$
k=A+B \theta[(1-C) z+C],
$$

where $\mathrm{z}$ is the water content at a given freezing degree, $\theta$ is the water content by volume and $\theta=\mathrm{nS}_{\mathrm{r}}, \mathrm{A}=\mathrm{k}_{\mathrm{s}}(1-n)$, $\mathrm{B}=\mathrm{k}_{\mathrm{i}}, \mathrm{C}=\mathrm{k}_{\mathrm{w}} / \mathrm{k}_{\mathrm{i}}$, where $\mathrm{k}_{\mathrm{i}}$ is the thermal conductivity of the ice. Sun et al. [35] showed that in the temperature range $0^{\circ} \mathrm{C}$ to $10^{\circ} \mathrm{C}$, thermal conductivity decreases with electrical resistance and can be expressed by the equation:

$$
\begin{array}{r}
k=1.97-0.0088 r, \text { where } r=r_{s}(1-n)+r_{a} n+ \\
\theta\left(r_{i} x-r_{a}\right),
\end{array}
$$

where $r_{s}, r_{a}, r_{i}$ are the electrical resistance of the solid part, air and ice respectively $[\Omega \mathrm{m}]$. In the temperature range $-10^{\circ} \mathrm{C}$ to $-20^{\circ} \mathrm{C}$, the equation for thermal conductivity has the form:

$$
k=1.72+9.92 r .
$$

The thermal conductivity varies linearly with the electrical resistance here.

\subsubsection{The model of $\mathrm{He}$ et al. [36]}

He et al. [36] proposed a new model to predict the effective thermal conductivity $k_{\text {eff }}$ of a soil from the matrix potential $\psi$ (ie at high water content). Using the 
analogy between $\mathrm{k}_{\text {eff }}(\psi)$ and water retention in soil proposed a function depending on the air entry point $\psi_{b}$ :

$$
k_{e f f}(\psi)=\left\{\begin{aligned}
k_{s a t}, & p F<\psi_{b} \\
A_{2} p F^{A_{3}}, & p F>\psi_{b}
\end{aligned}\right.
$$

where $A_{2}$ and $A_{3}$ are the fitting parameters, $p F$ is the full matrix potential range. This model can be used across the entire range of the matrix potential.

\subsubsection{The model of He et al. [37]}

He et al. [37] proposed a new method to estimate the thermal conductivity of soil solids $\mathrm{k}_{\mathrm{s}}$ with different textures and water content. Knowledge of the mineralogical composition of the soil is not required. This method can be used for fine-grained soil and land for which there is no measured $\mathrm{k}_{\text {sat. }}$. It then requires at least three measurements between $\mathrm{k}_{\mathrm{s}}$ and $\mathrm{k}_{\mathrm{sat}}$ :

$$
\begin{gathered}
k_{\text {eff }}= \\
\left\{\begin{array}{c}
k_{d r y}, \theta=0 \\
k_{d r y}+\left(k_{\text {sat }}-k_{d r y}\right) /\left[A_{4} \cdot \exp \left(\theta^{-B_{4}}\right)\right], \theta>0
\end{array}\right. \\
k_{\text {dry }}= \begin{cases}-0.58 n+0.5, & \text { grupa } 1 \\
-1.92 n+1.18, & \text { grupa } 2 \\
k_{\text {sat }}=k_{w}^{n} k_{s}^{1-n}, & \end{cases}
\end{gathered}
$$

where the coefficients $\mathrm{A}$ and $\mathrm{B}$ and the thermal conductivity of the constant part $\mathrm{k}_{\mathrm{s}}$ are the fitting parameters.

\subsection{Mathematical models}

Mathematical models are created from prediction models of other physical properties of soils, such as dielectric permittivity, magnetic permeability, electrical conductivity or hydraulic conductivity. They are calculated using specific mathematical algorithms. They take into account the thermal conductivity of individual soil components [24]. Mathematical models assume a simplified geometry of soil grains in order to obtain a mathematical relationship [9].

\subsubsection{The model of Ofrikhter et al. [5]}

Developed by Ofrikhter et al. [5] the cube model is used to estimate the thermal conductivity of the soil based on known soil parameters, such as soil porosity and the degree of water saturation. The soil is treated as a threephase medium consisting of air, water and a mineral part (Fig. 1) and there is no heat exchange due to heat and mass transfer through the groundwater. The model assumes that the heat flow is limited to a single direction parallel to the $\mathrm{Z}$ axis (Fig.2). The total heat flux $\mathrm{Q}_{\mathrm{tot}}$ passing through the cube is divided into individual fluxes $\mathrm{Q}_{i}$ passing through a different combination of soil components. The model assumes 5 paths of heat flow (Fig.2). The formula for the effective thermal conductivity of the soil is as follows:

$$
k_{e f f}=\frac{Q_{1}+Q_{2}+Q_{3}+Q_{4}+Q_{5}}{\Delta T \cdot l},
$$

where 1 is the length of the unit cube, $\Delta \mathrm{T}$ is the temperature gradient.

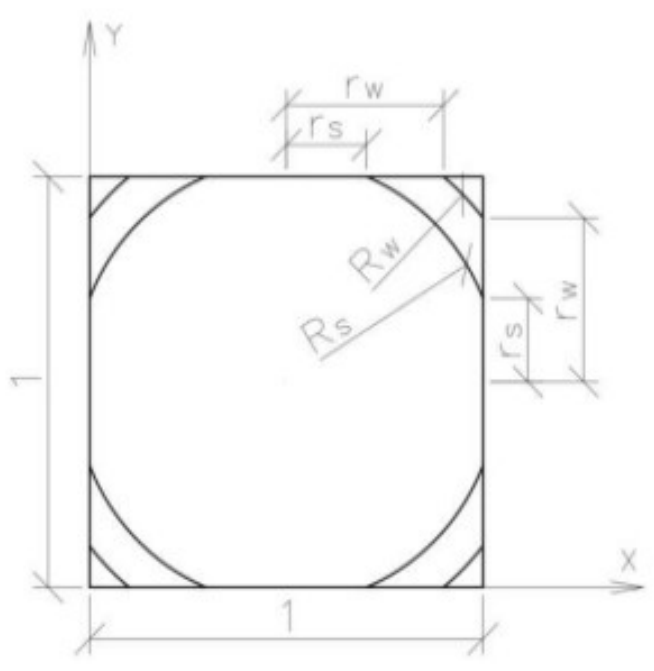

Fig. 1. Model for calculating heat flow in soils [5]

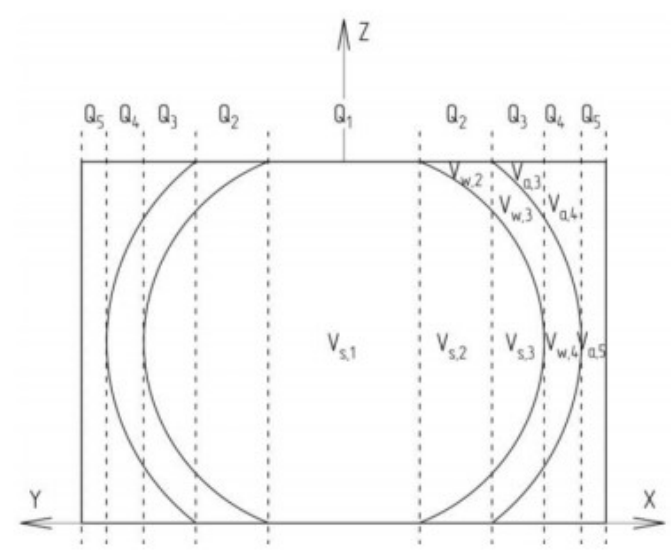

Fig. 2. Miter cut [5]

After substituting, the formula for effective thermal conductivity is:

$$
\begin{gathered}
k_{e f f}=\frac{S_{1}^{2}}{\frac{V_{s, 1}}{k_{S}}}+\frac{S_{2}^{2}}{\frac{V_{s, 2}}{k_{S}}+\frac{V_{w, 2}}{k_{w}}}+\frac{S_{3}^{2}}{\frac{V_{S, 3}}{k_{S}}+\frac{V_{w, 3}}{k_{w}}+\frac{V_{a, 3}}{k_{a}}}+\frac{S_{4}^{2}}{\frac{V_{w, 2}}{k_{w}}+\frac{V_{a, 4}}{k_{a}}}+ \\
\frac{S_{5}^{2}}{k_{S}},
\end{gathered}
$$

where $k_{s}$ is the effective conductivity of the mineral part, $\mathrm{k}_{\mathrm{w}}$ is the effective conductivity of the water, $\mathrm{k}_{\mathrm{a}}$ is the effective conductivity of the air. Thermal conductivity of water and air depends on temperature and is determined from the formulas:

$$
\begin{gathered}
k_{w}=0,552+2.34 \cdot 10^{-3} T-1,1 \cdot 10^{-5} \cdot T^{2}, \\
k_{a}=0,0237+0,000064 \cdot T .
\end{gathered}
$$

The thermal conductivity of the mineral part of the soil sample is determined from the measured thermal 
conductivity, temperature, porosity, and water saturation coefficient of the sample by any available means. The radius of the sphere reflecting the content of the mineral part and the water is determined from the formulas:

$$
\begin{gathered}
R_{s}=120,7 n^{6}-207,9 n^{5}+144,6 n^{4}-52,55 n^{3}+ \\
10,97 n^{2}-1,73 n+0,755, \\
R_{w}=120,7 a_{1}^{6}-207,9 a_{1}^{5}+144,6 a_{1}^{4}-52,55 a_{1}^{3}+ \\
10,97 a_{1}^{2}-1,73 a+0,755 \\
a_{1}=n-n \cdot S_{r} .
\end{gathered}
$$

This model is applicable to soils with porosity and water saturation within the specified limits:

$$
0,0349 \leq n \leq 0,4764, S_{r} \leq 1-\frac{0,0349}{n} .
$$

If the water saturation coefficient exceeds the value indicated in the roughness it is assumed that the soil is saturated, and the air contained in the soil has practically no effect on its thermal conductivity.

\subsubsection{The model of Zhu [38]}

Zhu [38] developed a new cell model to determine the effective thermal conductivity of an unsaturated porous medium. It treats the soil as a two-phase mixture consisting of a liquid part (which is a mixture of liquid and gas) and a solid part (Fig.3).

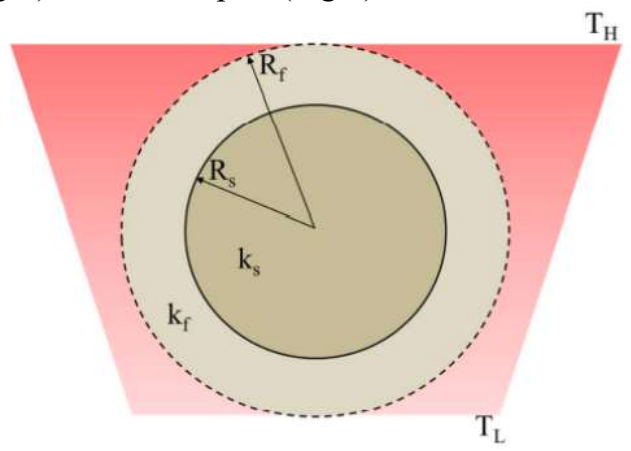

Fig. 3. Schematic diagram of a heat conduction cell model in an unsaturated medium to represent interactions between phases [38]

The thermal conductivity of mixed liquid phases is expressed as the volume-weighted average thermal conductivity of a gas and a liquid:

$$
\begin{gathered}
\frac{k_{e f f}}{k_{f}}= \\
\frac{\left(\frac{R_{S}}{R_{f}}\right)^{3}\left\{\left(k_{S} / k_{f}+2\right)\left[\left(\frac{R_{f}}{R_{S}}\right)^{3}-1\right]+6\left(k_{S} / k_{f}-1\right) \ln \left(\frac{R_{f}}{R_{S}}\right)+3\left(k_{S} / k_{f}\right)\right\}}{k_{S} / k_{f}+2-\left(k_{S} / k_{f}-1\right)\left(\frac{R_{S}}{R_{f}}\right)^{3}}
\end{gathered}
$$

where $\mathrm{k}_{\mathrm{f}}$ is the thermal conductivity of the mixed liquid phase (water and air) $[\mathrm{W} / \mathrm{mK}], \mathrm{k}_{\mathrm{s}}$ is the thermal conductivity of the solid phase $[\mathrm{W} / \mathrm{mK}], \mathrm{R}_{\mathrm{s}}$ is the radius of the solid particle and represents the average radius of the solid particles in unsaturated porous materials, $R_{f}$ is the radius mixed fluid outer shell and is related to the porosity of unsaturated porous materials.

The equation of effective thermal conductivity expressed as the ratio of $\mathrm{k}_{\mathrm{eff}}$ to porosity has the form:

$$
\frac{k_{e f f}}{k_{f}}=\frac{3 k_{S} / k_{f}-2\left(k_{S} / k_{f}-1\right)[n+(1-n) \ln (1-n)]}{3+n\left(k_{S} / k_{f}-1\right)} .
$$

It can also be expressed as the ratio of $\mathrm{k}_{\text {eff }}$ to the thermal conductivity of the liquid phase $\mathrm{k}_{\mathrm{l}}$ :

$$
\begin{gathered}
\frac{k_{\text {eff }}}{k_{l}}= \\
\frac{\left\{3\left(\frac{k_{s}}{k_{l}}\right)-2\left[\frac{k_{s}}{k_{l}}-S_{l}-\left(1-S_{l}\right)\left(\frac{k_{a}}{k_{l}}\right)\right][n+(1-n) \ln (1-n)]\right\}\left[S_{l}+\left(1-S_{l}\right) \frac{k_{a}}{k_{l}}\right]}{(3-n)\left[S_{l}+\left(1-S_{l}\right)\left(\frac{k_{a}}{k_{l}}\right)\right]+n\left(\frac{k_{s}}{k_{l}}\right)} .
\end{gathered}
$$

This model takes into account the effect of saturation with the water phase on the effective thermal conductivity.

\subsection{Numerical models}

Wen et al. [39] developed a model based on multiple linear regression (MLR) and artificial neural networks (ANN) for soils in the full range of saturation. The input parameters in the input layer are clay content, silt content, sand content, thermal conductivity of solids, thermal conductivity of dried soils, thermal conductivity of saturated soils, quartz content and porosity. Rizvi et al. [40] developed an artificial neural network (ANN) model based on a fast learning (DL) algorithm. This model is applicable to the calculation of the effective thermal conductivity of unsaturated sandy soils. It has one input layer (which receives three parameters: porosity, degree of saturation and quartz content), three hidden and one output. Zhang et al.[41] developed the ANN model. They developed separate predictive models for clay, silt, silty sand, fine sand and coarse sand, as well as a generalized model covering five different soil types. The input parameters for individual models were humidity and dry density. For the generalized model, the input parameters were moisture, dry density, clay content, and quartz content (clay and quartz represent changes in gradation and mineralogy). Shrestha and Wuttke [42] used an artificial neural network approach to predict the thermal conductivity of geomaterials taking into account their gradation, porosity and mineralogy. The input parameters for the input layer are porosity, quartz content, curvature factor and uniformity factor.

\section{Conclusions}

There are many models of the thermal conductivity of the soil in the literature. However, none of them is universal enough to be used in any case. Therefore, there is a need to constantly develop new models. The latest models for calculating the thermal conductivity of soils are presented above, but they are also not universal models with a wide range of applications. However, this compilation will help you find an equation for 
calculating thermal conductivity that can be adapted to the specific case under analysis.

\section{References}

1. T. Zhang, C. Wanga, S. Liub, N. Zhangc, T. Zhang. Assessment of soil thermal conduction using artificial neural network models. Cold Reg Sci and Technol, 169, (2020). doi: 10.1016/j.coldregions.2019.102907

2. S. K. Haigh. Thermal Conductivity of Sands. Geotechnique, , 62 (7): 617-25 (2012). doi: 10.1680/geot.11.P.043.

3. Y. Zhao, B. Si, Z. Zhang, M. Li, H. He, R. L. Hill. A new thermal conductivity model for sandy and peat soils. Agricultural and Forest Meteorology, 274: 95-105 (2019).

4. D. Barry-Macaulay, A. Bouazza, B. Wang, R.M. Singh. Evaluation of soil thermal conductivity models. Canadian Geotech J, 52 (11): 1892-1900 (2015). doi.org/10.1139/cgj-2014-0518

5. I. Ofrikhter, A. Zaharov, A. Ponomaryov, N. Likhacheva. Modeling heat transfer process in soils. MATEC Web of Conferences, 251 (4): 02048 (2018). doi.org/10.1051/matecconf/201825102048

6. O.T. Farouki. Thermal properties of soils. Series Rock Soil Mech, 11:1-136 (1986).

7. H. He, D. He, J. Jin, K. M. Smits, M. Dyck, Q. Wu, B.Ch. Si, J. Lv. Room for Improvement: A Review and Evaluation of 24 Soil Thermal Conductivity Parameterization Schemes Commonly Used in Land-Surface, Hydrological, and Soil-VegetationAtmosphere Transfer Models. Earth-Sci Rev, 211:103419

(2020). doi:10.1016/J.EARSCIREV.2020.103419

8. M. Rerak. Selected Soil Thermal Conductivity Models. E3S Web of Conferences, 13:4-7 (2017). doi:10.1051/e3sconf/20171302003

9. N. Zhang, Z. Wang. Review of Soil Thermal Conductivity and Predictive Models. Int J Therm $\begin{array}{llll}\text { Sci } & \text { 117:172-83 (2017). }\end{array}$ 10.1016/j.ijthermalsci.2017.03.013

10. A. Różański, Natalia Kaczmarek. Empirical and Theoretical Models for Prediction of Soil Thermal Conductivity: A Review and Critical Assessment. Studia Geotechnica et Mechanica, 42 (4):330-40 (2020). doi:10.2478/sgem-2019-0053

11. M.S. Kersten. Thermal properties of soil. Bull Univ Minn Inst Technol, 52:1-225 (1949)

12. D.A. De Vries. The thermal properties of soils. In: W.R. van Wijk, Ed., Physics of Plant Environment. North Holland Publishing Co., Amsterdam, 210235 (1963)

13. D.A. De Vries, N.H. Afgan. Heat and mass transfer in the biosphere. John Wiley and Sons, 1975.

14. O. Johansen. Thermal conductivity of soils. Ph.D. thesis. University of Trondheim, Trondheim, Norway. US Army Corps of Engineers, Cold Regions Research and Engineering Laboratory, Hanover, N. H. CRREL Draft English Translation. $637,1975$.
15. P. Ocłoń, P. Cisek, M. Pilarczyk, D. Taler. Numerical Simulation of Heat Dissipation Processes in Underground Power Cable System Situated in Thermal Backfill and Buried in a Multilayered Soil. Energ Convers Manage, 95: 352-70 (2015). doi:10.1016/j.enconman.2015.01.092

16. C.D. Peters-Lidard, E. Blackburn, X. Liang, E.F. Wood. The effect of soil thermal conductivity parameterization on surface energy fluxes and temperatures. Journal of the Atmospheric Sciences, 55:1209-1224 (1998). doi.org/10.1175/15200469(1998)055<1209:TEOSTC $>2.0$. CO;2

17. N. Zhang, X. Yu, A. Pradhan, AJ Puppala. A new generalized soil thermal conductivity model for sand-kaolin clay mixtures using thermo-time domain reflectometry probe test. Acta Geotech, 12:739-752 (2017). doi.org/10.1007/s11440-0160506-0

18. S.X. Chen. Thermal Conductivity of Sands. Heat Mass Trans, 44 (10):1241-46 (2008). doi:10.1007/s00231-007-0357-1

19. S.K. Haigh. Thermal Conductivity of Sands.

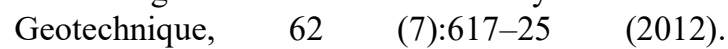
doi:10.1680/geot.11.P.043

20. J. Côté, J.M. Konrad. 2005. Thermal Conductivity of Base-Course Materials. Canadian Geotechnical Journal, 42 (1):61-78 (2005). doi: 10.1139/t04-081

21. J. Côté, J.M. Konrad. A Generalized Thermal Conductivity Model for Soils and Construction Materials. Canadian Geotechnical Journal, 42 (2): 443-58 (2005). doi: 10.1139/t04-106

22. Y. Lu, S. Lu, R. Horton, T. Ren. An empirical model for estimating soil thermal conductivity from texture, water content, and bulk density. Soil. Sci. Soc. Amer. J., 78: 1859-1868 (2014). doi:10.2136/sssaj2014.05.0218

23. H. He, Y. Zhao, M.F. Dyck, B. Si, H. Jin, J. Lv, J.A. Wang. A modified normalized model for predicting effective soil thermal conductivity, Acta Geotechnica, 12 (6): 1281-1300 (2017). doi 10.1007/s11440-017-0563-Z

24. N. Lu, Y. Dong. Closed-Form Equation for Thermal Conductivity of Unsaturated Soils at Room Temperature. J Geotech Geoenviron, 141 (6):04015016. doi:10.1061/(asce)gt.19435606.0001295

25. N. Zhang, X. Yu, A. Pradhan, A.J. Puppal. Thermal conductivity of quartz sands by thermo-time domain reflectometry probe and model prediction. Journal of Materials in Civil Engineering, 27 (12): 04015059 (2015). doi:10.1061/(asce)mt.19435533.0001332

26. N. Zhang, X. Yu, A. Pradhan, A.J. Poppala. A new generalized soil thermal conductivity model for sand-kaolin clay mixtures using thermo-time domain reflectometry probe test. Acta Geotechnica, 12 (4): 739-752 (2016). doi:10.1007/s11440-0160506-0

27. V. Tarnawski, W.H. Leong. Advanced Geometric Mean Model for Predicting Thermal Conductivity of Unsaturated Soils. Int J Thermophys, 37 (2): 142 (2016). doi:10.1007/s10765-015-2024-y 
28. B. Tong, Z. Gao, R. Horton, Y. Li, L. Wang. An empirical model for estimating soil thermal conductivity from soil water content and porosity. Journal of Hydrometeorology, 17 (2): 601-13 (2016). doi: 10.1175/JHM-D-15-0119.1

29. Z. Wang, N. Zhang, J. Ding, Q. Li, J. Xu. Thermal conductivity of sands treated with microbially induced calcite precipitation (MICP) and model prediction. International Journal of Heat and Mass Transfer, (2019). doi.org/10.1016/j.ijheatmasstransfer.2019.118899

30. R. Li, L. Zhao, T. Wu, Q. Wang, Y. Ding, J. Yao, X. Wu, G. Hu, Y. Xiao, Y. Du, X. Zhu, Y. Qin, S. Yang, R. Bai, E. Du, G. Liu, D. Zou, Y. Qiao, J. Shi. Soil thermal conductivity and its influencing factors at the Tanggula permafrost region on the QinghaiTibet Plateau. Agricultural and Forest Meteorology, 264: 235-246

(2019).

doi.org/10.1016/j.agrformet.2018.10.011

31. Z. Tian, T. Ren, J.L. Heitman, R. Horton. Estimating thermal conductivity of frozen soils from air-filled porosity. Soil Science Society of America Journal, (2020). doi.org/10.1002/saj2.20102

32. B. Tian, Y. Kong, Y. Gong, C. Ye, Z. Pang, J. Wang, P. Qin. Thermal conductivity characterisation of shallow ground via correlations with geophysical parameters. Engineering Geology, 272 (2020). doi:10.1016/j.enggeo.2020.105633

33. Y. Xiao, G. Ma, B. Nan, J.S. McCartney. Thermal conductivity of granular soil mixtures with contrasting particle shapes. J Geotech Geoenviron, $146 \quad$ (5):06020004 (2020). doi:10.1061/(ASCE)GT.1943-5606.0002243

34. X. Song, H. Fan, J. Liu, X. Yang. An improved thermal conductivity model for unsaturated clay. KSCE Journal of Civil Engineering, 24: 2364-71 (2020). doi:10.1007/s12205-020-1812-5

35. Q. Sun, C. Lyu, W. Zhang. The relationship between thermal conductivity and electrical resistivity of silty clay soil in the temperature range $-20 \mathrm{C}$ to $10 \mathrm{C}$. Heat and Mass Transfer, 56 (6): 2007-13, (2020). doi:10.1007/s00231-020-02813-0

36. H. He, M. Dyck, J. Lv. A new model for predicting soil thermal conductivity from matric potential. J Hydrol, 589:125167

(2020). doi.org/10.1016/j.jhydrol.2020.125167

37. H. He, M. Li, M. Dyck, B. Si, J. Wang, J. Lv. Modelling of soil solid thermal conductivity. International Communications in Heat and Mass Transfer, 116: $104602 \quad$ (2020). doi.org/10.1016/j.icheatmasstransfer.2020.104602

38. J. Zhu. Unsaturated cell model of effective thermal conductivity of soils. SN Appl. Sci., 2: 1395 (2020). doi.org/10.1007/s42452-020-03211-1

39. H. Wen, J. Bi, D. Guo. Calculation of the thermal conductivities of fine-textured soils based on multiple linear regression and artificial neural networks. Eur J Soil Sci, 71:568-579 (2020). doi.org/10.1111/ejss.12934

40. Z.H. Rizvi, H.H. Zaidi, S.J. Akhtar, A.S. Sattari, F. Wuttke. Soft and hard computation methods for estimation of the effective thermal conductivity of sands. Heat and Mass Transfer, 56: 1947-59 (2020). doi.org/10.1007/s00231-020-02833-w

41. N. Zhang, H. Zou, L. Zhang, A.J. Puppala, S. Liu, G. Cai. A unified soil thermal conductivity model based on artificial neural network. International Journal of Thermal Sciences, 155:106414 (2020). doi.org/10.1016/j.ijthermalsci.2020.106414

42. D. Shrestha, F. Wuttke. Predicting the effective thermal conductivity of geo-materials using artificial neural network. W35 Web of Conferences, 205: $\quad 04001$ (2020). doi.org/10.1051/e3sconf/202020504001 